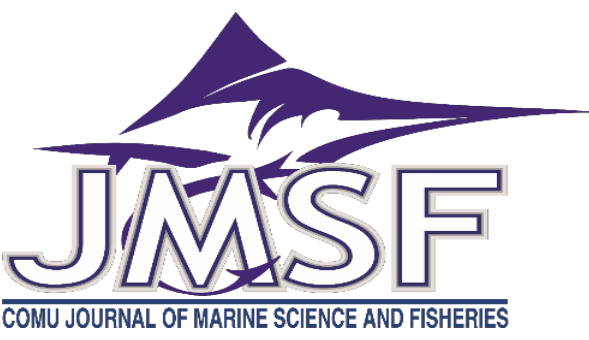

RESEARCH ARTICLE

\title{
The Effects of Different Hanging Ratios on Gillnet Selectivity for Blotched Picarel (Spicara maena) in Northern Aegean Coasts of Turkey
}

\author{
Uğur Altınağaç ${ }^{1 *}$, Adnan Ayaz $^{1}$, Alkan Öztekin $^{1}$, Uğur Özekinci ${ }^{1}$ \\ Cenkmen Ramazan Beğburs ${ }^{2}$ \\ ${ }^{1}$ Çanakkale Onsekiz Mart Üniversitesi Deniz Bilimleri ve Teknolojisi Fakültesi \\ ${ }^{2}$ Akdeniz Üniversitesi Su Ürünleri Fakültesi \\ Correspondent: ualtinagac@yahoo.com \\ Received: 01.06.2020 Accepted: 15.06 .2020 \\ Uğur Altınăgaç: Orcid 0000-0002-3638-9834, Adnan Ayaz: Orcid 0000-0003-4839-9244, Alkan Öztekin: Orcid 0000-0003-3914-9788, \\ Uğur Özekinci: Orcid 0000-0003-2207-0168, Cenkmen Ramazan BEĞBURS: Orcid 0000-0002-6426-721X,
}

\begin{abstract}
How to cite this article: Altınağaç, U., Ayaz, A., Öztekin, A., Özekinci, U., \& Beğburs, C.R., (2020). The effects of different hanging ratios on gillnet selectivity for blotched picarel (Spicara maena) in Northern Aegean Coasts of Turkey. COMU J. Mar. Sci. Fish, 3(1):
\end{abstract} 27-37. DOI: $10.46384 /$ jmsf.746515

\begin{abstract}
The study was conducted at 0-30 meters depth, in the Northern Aegean coast of Turkey, between October 15, 2015 - October 15, 2017. In the study, 9 different gillnets (Mullet nets) having 18-20-22 mm mesh size and 0.35-0.50-0.65 hanging ratio were used. The aim of this study was to determine the selectivity of these nets with different hanging ratios in the fishing of blotched picarel (Spicara maena). In the selectivity calculations made for this species, the SELECT model was used as "bi-modal" for gillnets with $\mathrm{E}=0.35$ hanging ratio, "log normal " for $\mathrm{E}=0.50$ hanging ratio and "normal scale" for $\mathrm{E}=0.65$ hanging ratio, model gave the best results. No selectivity difference depending on different hanging ratio could be determined for the blotched picarel that caught the highest number of fish on the trial nets. However, it has been determined that the optimum length and gillnets selectivity curves calculated for $18 \mathrm{~mm}$ mesh sized nets contain the values close to the sexual maturity length calculated for the blotched picarel.
\end{abstract}

Keywords: Hanging Ratio, Blotched Picarel, Gillnet, Selectivity, North Aegean

\section{Türkiye'nin Kuzey Ege Kıyılarında Sade Uzatma Ağlarında Farklı Donam Faktörlerinin İzmarit (Spicara maena) Balığı Seçiciliği Üzerine Etkileri}

Özet: Çalışma, Türkiye'nin Kuzey Ege kıyılarında 15 Ekim 2015 - 15 Ekim 2017 tarihleri arasında 0-30 metre derinlikte yürütülmüş̧ür. Çalışmada, $18-20-22 \mathrm{~mm}$ göz genişliği ve 0,35-0,50-0,65 donam faktörüne sahip 9 farklı sade uzatma ağı (Barbun ağları) kullanılmıştır. Bu çalışmanın amacı farklı donam faktörlerine sahip bu ağların izmarit balığı (Spicara maena) avcılığındaki seçicilik değerlerinin belirlenmesidir. $\mathrm{Bu}$ balık için yapılan seçicilik hesaplamalarında, SELECT model kullanılmıș, $E=0,35$ donam faktöründeki ağlar için "bi-modal", $E=0,50$ donam faktörü için "lognormal", $E=0,65$ donam faktörü için ise "normal scale" modeli en iyi sonucu vermiştir. Deneme ağlarına en fazla yakalanan izmarit balığı için donam faktörü değişikliğine bağlı bir seçicilik farkı belirlenememiştir. Ancak $18 \mathrm{~mm}$ göz genișliğindeki ağlar için hesaplanan optimum boy ve seçicilik eğrisi değerlerinin, izmarit balığı için hesaplanan ilk üreme boyuna yakın değerleri içerdiği belirlenmiştir.

Anahtar Kelimeler: Donam Faktörü, İzmarit Balığı, Uzatma Ağı, Seçicilik, Kuzey Ege

Giriş

Galsama ağları, mantarlar ve kurșunlar yardımıyla suda dik duran, bir veya daha çok ağ duvarlarından oluşan, balık veya diğer su ürünlerinin galsamalarından veya vücudun diğer kısımlarından ağa takılarak yakalanması amacıyla, deniz ve iç sularda; yüzey, orta su ve dipte kullanılan av araçlarıdır (Kara, 1992). Ayrıca, genellikle pasif olarak kullanılmakla beraber aktif olarak da kullanılmaktadır (Kara, 1992; Ünsal ve Kara, 1996; Brandt, 1984). 
Uzatma ağlarında seçiciliği etkileyen pek çok etken olmakla beraber, ana faktörün göz genişliği olduğu birçok araştırmacı tarafından bildirilmiştir (Brandt, 1984; Ayaz ve diğ., 2010; Kumova, 2013; Kumova ve diğg., 2015; Yüksel ve Aydın, 2012). A $\breve{g}$ göz genişliği yanında ağın elastikiyeti, ağ ipinin esnekliği, sıkılığı, kalınlığı ve görünürlüğü, ağın kullanılma yöntemi, balığın vücut şekli ve davranışı, pektoral alan dişında balığın ağ gözüne yakalanma şeklinin etkili olduğu bildirilmiştir (Clark, 1960; Hamley, 1975; Özdemir ve diğ., 2005; Yüksel ve Aydın, 2012). Seçiciliği etkilediği düşünülen faktörlerden birisi de donam faktörüdür. Donam faktörü; ağ yapımında, ağın mantar ve kurşun yakası boyunca ne kadar gergin olduğunun bir ölçüsüdür. Donatılmış bir ağda, yaka uzunluğunun, orijinal (donatılmamış) ağın uzunluğuna bölünmesiyle elde edilen bir ölçüdür (Hubert ve diğ., 2012). Diğer bir ifade ile bir birim yakaya donatılan ağ boyudur (Hoşsucu, 2002; Yüksel ve Aydın, 2012; Karlsen ve Bjarnason, 1987).

Ağın su içerisindeki, göz açıklığının şekli, donam faktörü ile ilişkilidir ve tür seçiciliğini etkileyebileceği birçok araştırmacı tarafindan belirtilmiştir (Clark, 1960; Hamley, 1975; Yüksel ve Aydın, 2012; Karlsen ve Bjarnason,1987). Donam faktörü, balıkların ağa dolanarak, gözleyerek veya farklı vücut uzantılarından takılarak yakalanmasında etkilidir. Donatılan ağların donam faktörü azaldıkça, aynı türe ait iri bireylerin, dolanarak yakalanma ihtimali artmaktadir (Karlsen ve Bjarnason, 1987). Donam faktörü artması ile de balıkların yakalanması daha çok galsamalarından ağı gözleyerek olmaktadır.
Avrupa kıyılarındaki deniz balıkçılığında, yassı balıkların avcılığında kullanılan ticari uzatma ağlarının donam faktörleri 0,25 ile 0,65 arasında değiştiği, fusiform balıkların avcılığında kullanılan ağların ise 0,4 ile 0,6 donam faktörleri arasında olduğu bildirilmiştir (Hovgard ve Lassen, 2000).

Barbun balıkları (Mullus sp.) Türkiye demersal balık türleri içerisinde, yüksek ticari öneme sahip türlerdir (Kalaycı ve Yeşilçicek, 2012; Dinçer ve Bahar, 2008; Bolat ve Tan, 2017). Galsama ağların hedefi barbun ve tekir (Mullus sp) türleri olmakla beraber pek çok tür yan ürün olarak bu ağlara yakalanmaktadır. İzmarit (Spicara maena) balığı da bu ağlarla yapılan avcılıkta yan ürün olarak yoğun av vermektedir. Ancak, bu türün (İzmarit balığı) avcılığında kullanılan galsama ağlarında donam faktörünün seçiciliğine olan etkisi üzerine yapılan araştırma bulunmamaktadır. Bu çalışmada, barbun balığı avcılığında yoğun olarak kullanılan sade galsama ağlarında, yan ürün olarak yakalanan izmarit balığı için, donam faktörünün seçiciliğe olan etkilerini ortaya koymak ve İzmarit balığ popülasyonunun sürdürülebilirliği için en uygun donam faktörünün belirlemesi amaçlanmıştır.

\section{Materyal ve Yöntem}

Çalışma, Ekim 2015 - Ekim 2017 tarihleri arasında Kuzey Ege'de 0-30 m derinlikler arasında ticari balıkçılık faaliyetlerinin yapıldığı alanlarda yürütülmüştür. Çanakkale ve Gökçeada kıyılarında toplamda 37 avcılık operasyonu gerçekleştirilmiştir (Şekil 1).

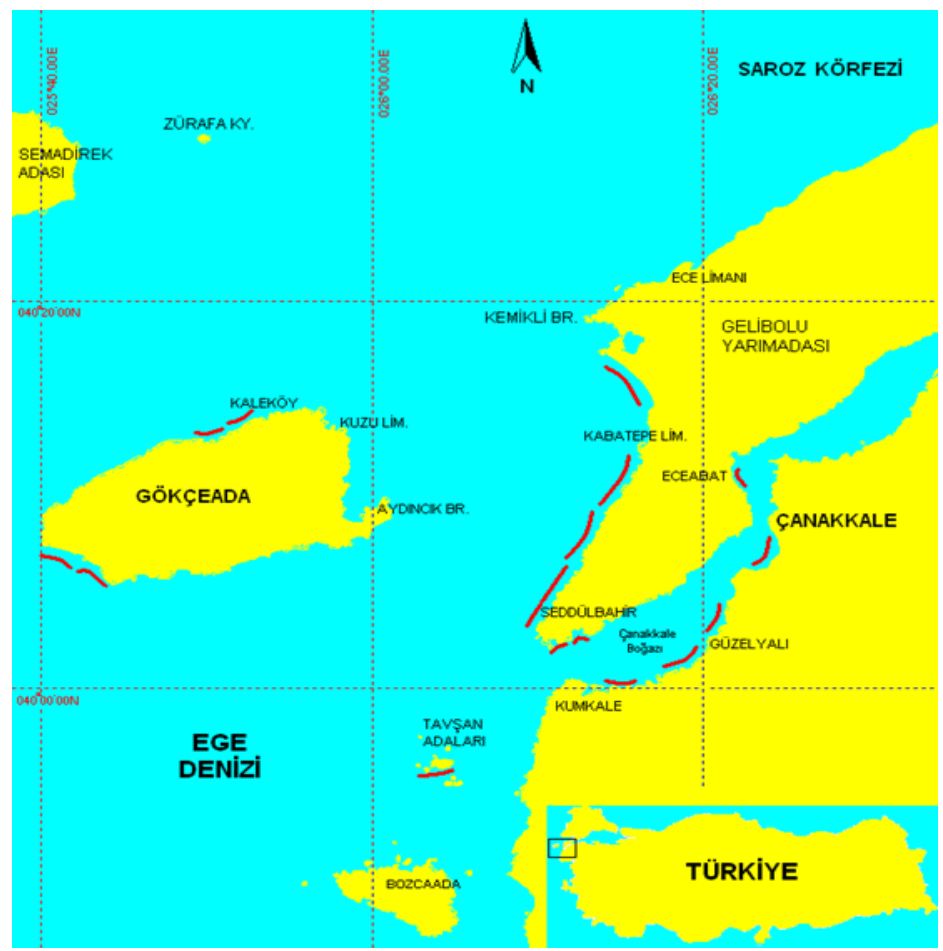

Şekil 1. Çanakkale ve Gökçeada kıyılarındaki örnekleme sahaları 
Çalışmada, $18-20$ ve $22 \mathrm{~mm}$ göz genişliğindeki ağlar $0,35-0,50$ ve 0,65 donam faktörü ile donatılarak toplam 9 farklı ağ tipi oluşturulmuştur. Ağların ip kalınlığ1, multiflament 210 denye/3 numara olup ağ göz derinliği 40 gözdür. Ağların teknik özelliklerini gösteren plan Şekil 2'de verilmiştir.

Çalışmada kullanılan ağlar 1 paket $(200 \mathrm{~m}$ uzunluk, 40 vertikal göz yüksekliğinde) ağdan tasarlanmasına karşın farklı donam faktörlerinde yapıldığında $E=0,35$ donam faktöründeki ağ $70 \mathrm{~m}$, $\mathrm{E}=0,50$ donam faktöründeki ağ $100 \mathrm{~m}$ ve $\mathrm{E}=0,65$ donam faktöründeki ağlar $130 \mathrm{~m}$ uzunluk vermiştir. Bütün ağlar birbiri arkasına bağlanarak denize atılmış ve pasif olarak yarı dönek yöntemiyle kullanılmıştır. Ağların suda kalma süresi gün uzunluğu açısından yaz ve kıș mevsimlerinde değişiklik göstermekte olup, ortalama 3 saat civarı suda kalmıştır.

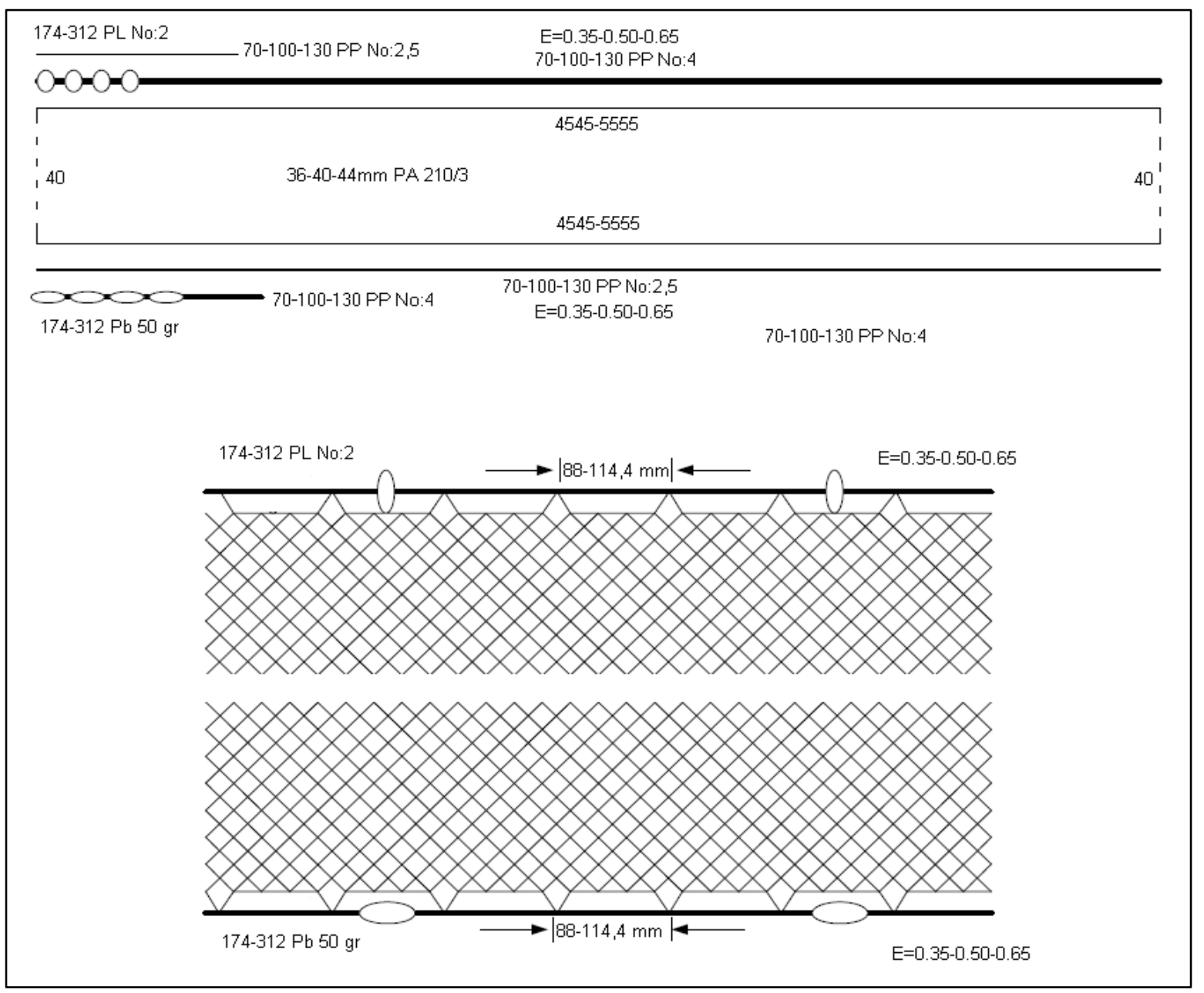

Şekil 2. Deneme ağlarının teknik planı

\section{Seçicilik Hesaplama Yöntemi}

Seçiciliği belirlemede, Millar (1992) ve Millar ve Holst (1997) tarafindan geliştirilen SELECT (Share Each Lengthclass Catch Total) metot kullanılmıştır. $\mathrm{Bu}$ metotta $j$ boyutundaki ağ gözü açıklığına yakalanan $l$ boyundaki balıkların sayısı $n_{l j}$ bir Poisson dağılımına sahip olduğu farz edilir ve aşağıdaki şekilde ifade edilir.

$$
\mathrm{n}_{l j} \approx \mathrm{n}_{l j} \approx \text { Pois }\left(p_{j} \lambda_{l} r_{j}(l)\right)
$$

Burada; $\lambda_{l}$ ağ ile karşılaşan $l$ boyundaki balıkların bolluğu; $p_{j}$ (l): göreceli balık yoğunluğunu (j ağ göz genişliğinin avlayabileceği 1 boyundaki balıkların göreceli bolluğu) ifade etmektedir. $J$ göz genişliğine sahip ağlara temas eden $l$ boyundaki balık sayısının Poisson dağılımı $p_{j}(l) \lambda_{l}$ şeklindedir. $r_{j}(l) \quad j$ ağ göz genişliği için seçicilik eğrisini oluşturmaktadır.

$\mathrm{n}_{l j}$ 'nin log-likelihood dağılımı aşağıdaki gibidir;

$$
\sum_{l} \sum_{j}\left\{n_{l} \log \left[p_{j} \lambda_{l} r_{j}(l)\right]-p_{j} \lambda_{l} r_{j}(l)\right\}
$$

Arazi çalışmaları sonucunda elde edilen veriler PASGEAR II version 2.3 (Kolding ve Skålevik, 2017) bilgisayar programı ile analiz edilmiştir. Program SELECT (Millar, 1992; Millar ve Fryer, 
1999; Millar ve Holst, 1997; Holst ve diğ., 1998) metodunu esas alarak 5 farklı modele (Normal location, normal scale, log-normal, gamma ve bimodal) ait parametreleri hesaplamaktadır. $\mathrm{Bu}$ modeller içinde en düşük sapma değeri dikkate alınarak en uygun modele göre seçicilik eğrileri çizdirilmiş ve optimum yakalama boylarının ve yayılım değerleri hesaplanmıştır. SELECT metoda ait model denklemleri aşağıda verilmiştir.

Normal Location :

$$
\exp \left(-\frac{\left(L-k \cdot m_{j}\right)^{2}}{2 \sigma^{2}}\right)
$$

Normal Scale ;

$$
\exp \left(-\frac{\left(L-k_{1} \cdot m_{j}\right)^{2}}{2 k_{2}^{2} \cdot m_{j}^{2}}\right)
$$

Log-Normal ;

$$
\frac{1}{L} \exp \left(\mu+\log \left(\frac{m_{j}}{m_{1}}\right)-\frac{\sigma^{2}}{2}-\frac{\left(\log (L)-\mu-\log \left(\frac{m_{j}}{m_{1}}\right)\right)^{2}}{2 \sigma^{2}}\right)
$$

Gamma ;

$$
\left(\frac{L}{(\alpha-1) \cdot k \cdot m_{j}}\right)^{\alpha-1} \exp \left(\alpha-1-\frac{L}{k \cdot m_{j}}\right)
$$

Bi-modal ;

$$
\exp \left(-\frac{\left(L-k_{1} \cdot m_{j}\right)^{2}}{2 k_{2}^{2} \cdot m_{j}^{2}}\right)+c \cdot \exp \left(-\frac{\left(L-k_{3} \cdot m_{j}\right)^{2}}{2 k_{4}^{2} \cdot m_{j}^{2}}\right)
$$

\section{Bulgular}

Çalışma boyunca gerçekleştirilen 37 adet balıkçılık operasyonu sonucunda 26 familyaya ait 51 tür avlanılmış, toplamda 6961 adet ve 365,977 $\mathrm{kg}$ balık yakalanmıştır. Denemelerde ağırlık olarak, iskorpit (Scorpaena porcus) 71,9 kg (\%19,64), 1109 adet $(\% 15,93)$, tekir (Mullus surmuletus) 62,5 $\mathrm{kg}(\% 17,09), 1008$ adet $(\% 14,48)$ balıkları ile ilk iki sirada yer alırken, izmarit (Spicara maena) $52,28 \mathrm{~kg}$ $(\% 14,28)$ ile üçüncü sırada, $1226(\% 17,61)$ adet ile birinci sirada yakalanma oranına sahiptir. Deneme ağlarına yakalanan izmarit balıklarının maksimum, minimum ve ortalama boy ve ağırlıkları Tablo 1'de verilmiştir. Donam faktörü olarak incelendiğinde de $\mathrm{E}=0,35$ donam faktöründeki ağ gurubu diğerlerine göre fazla av yapmıştır. Denemelerde toplam av açısından değerlendirildiğinde en fazla balığı 18

\begin{tabular}{|c|c|c|c|c|c|c|c|c|}
\hline \multirow{2}{*}{$\begin{array}{c}\text { Göz Genişliği } \\
(\mathrm{mm})\end{array}$} & \multirow{2}{*}{ N sayısı } & \multicolumn{3}{|c|}{ Toplam Boy (cm) } & \multicolumn{3}{|c|}{ Ağırlık (g) } & \multirow{2}{*}{$\begin{array}{l}\text { Donam } \\
\text { Faktörü }\end{array}$} \\
\hline & & Min. & Maks. & Ortalama & Min. & Maks. & Ortalama & \\
\hline 18 & 352 & 11,8 & 17,7 & $14,06 \pm 0,75$ & 19 & 63 & $33,86 \pm 1,8$ & \\
\hline 20 & 135 & 11,2 & 19,2 & $16,29 \pm 1,40$ & 17 & 78 & $53,13 \pm 4,57$ & $\mathrm{E}=0,35$ \\
\hline 22 & 61 & 14,1 & 18,7 & $16,55 \pm 2,12$ & 37 & 80 & $56,25 \pm 7,20$ & \\
\hline 18 & 157 & 12,1 & 19 & $14,29 \pm 1,14$ & 20 & 86 & $34,7 \pm 2,77$ & \\
\hline 20 & 59 & 12 & 17,8 & $15,65 \pm 2,04$ & 16 & 80 & $49,81 \pm 6,48$ & $E=0,50$ \\
\hline 22 & 66 & 12,6 & 19,1 & $16,12 \pm 1,98$ & 22 & 98 & $50,5 \pm 6,22$ & \\
\hline 18 & 152 & 11,8 & 17,5 & $14,4 \pm 1,17$ & 16 & 67 & $34,54 \pm 2,80$ & \\
\hline 20 & 187 & 11,7 & 18,9 & $16,07 \pm 1,17$ & 28 & 75 & $49,63 \pm 3,63$ & $E=0,65$ \\
\hline 22 & 57 & 14,7 & 19,2 & $17,24 \pm 2,28$ & 43 & 98 & $61,5 \pm 8,14$ & \\
\hline
\end{tabular}
$\mathrm{mm}$ göz genişliğindeki ağlar yakalamıştır. Yakalanan balıkların boy dağılımları $11,2 \mathrm{~cm}$ ile 19,2 cm arasında değişmiştir (Tablo 1).

Tablo 1. Denemelerde ağlara yakalanan izmarit balıklarının minimum, maksimum, ortalama boy ve ağırlıkları

Deneme ağlarına yakalanan balıkların boy dağılımları ile yapılan seçicilik analizlerinde, $\mathrm{E}=0,35$ donam faktöründeki ağlarda en iyi sonucu bi-model, $\mathrm{E}=0,50$ donam faktöründeki ağlarda lognormal, $\mathrm{E}=0,65$ donam faktöründeki ağlarda ise normal scale modeli en iyi sonucu vermiştir. $\mathrm{Bu}$ modellerin seçicilik parametreleri Tablo 2'de 
verilmiştir. En iyi sonuçların elde edildiği modellere göre deneme ağlarının optimum yakalama boyları ve eğrilerin yayılım değerleri hesaplanmıştır. $\mathrm{Bu}$ değerler Tablo 3'te görülmektedir. Tablo 3 incelendiğinde ağların izmarit balığı için optimum yakalama boyları ve yayılım değerlerinin çok fazla farklılık göstermediği görülmektedir.

Tablo 2. Deneme ağlarına yakalanan izmarit balığı için hesaplanan seçicilik parametre değerleri

\begin{tabular}{|c|c|c|c|c|c|}
\hline Model & Parametre & $\begin{array}{l}\text { Model } \\
\text { Sapması }\end{array}$ & $P$ değeri & S. D. & $\begin{array}{l}\text { Donam } \\
\text { Faktörü }\end{array}$ \\
\hline $\begin{array}{l}\text { Normal } \\
\text { Location }\end{array}$ & $(\mathrm{k} ; \sigma)=(8,794 ; 1,316)$ & 87,557 & 0,0000001 & 19 & \multirow{5}{*}{0,35} \\
\hline Normal Scale & $\left(\mathrm{k}_{1} ; \mathrm{k}_{2}\right)=(8,844 ; 0,634)$ & 68,812 & 0,0000001 & 19 & \\
\hline Lognormal & $\left(\mu_{1} ; \sigma\right)=(2,769 ; 0,078)$ & 76,14 & 0,0000001 & 19 & \\
\hline Gamma & $(k ; \alpha)=(0,05 ; 176,143)$ & 73,077 & 0,0000001 & 19 & \\
\hline Bimodal & $\begin{array}{l}(\mathrm{k} 1, \mathrm{k} 2, \mathrm{k3}, \mathrm{k4}, \mathrm{w})= \\
(8,83 ; 0,602 ; 9,667 ; 1,687 ; 0,01)\end{array}$ & 61,27 & 0,0000001 & 16 & \\
\hline $\begin{array}{l}\text { Normal } \\
\text { Location }\end{array}$ & $(\mathrm{k} ; \sigma)=(8,634 ; 1,795)$ & 50,396 & 0,000194 & 20 & \multirow{5}{*}{0,5} \\
\hline Normal Scale & $\left(\mathrm{k}_{1} ; \mathrm{k}_{2}\right)=(8,743 ; 0,868)$ & 46,855 & 0,0000614 & 20 & \\
\hline Lognormal & $\left(\mu_{1} ; \sigma\right)=(2,759 ; 0,107)$ & 44,025 & 0,001493 & 20 & \\
\hline Gamma & $(\mathrm{k} ; \alpha)=(0,094 ; 93,190)$ & 44,528 & 0,001278 & 20 & \\
\hline Bimodal & Hesaplanamadı & & & & \\
\hline $\begin{array}{l}\text { Normal } \\
\text { Location }\end{array}$ & $(\mathrm{k} ; \sigma)=(8,611 ; 1,057)$ & 44,41 & 0,000504 & 18 & \multirow{5}{*}{0,65} \\
\hline Normal Scale & $\left(k_{1} ; k_{2}\right)=(8,653 ; 0,525)$ & 42,067 & 0,001082 & 18 & \\
\hline Lognormal & $\left(\mu_{1} ; \sigma\right)=(2,745 ; 0,062)$ & 44,522 & 0,000486 & 18 & \\
\hline Gamma & $(\mathrm{k} ; \alpha)=(0,033 ; 262,633)$ & 43,219 & 0,000745 & 18 & \\
\hline Bimodal & Hesaplanamad 1 & & & & \\
\hline
\end{tabular}

Tablo 3. İzmarit balığg için hesaplanan optimum yakalama boyu ve yayılım değerleri

\begin{tabular}{cccc}
\hline Göz Genişliği & $\begin{array}{c}\text { Optimum yakalama Boyu } \\
(\mathbf{c m})\end{array}$ & Yayılım (cm) & Donam Faktörü \\
\hline $18 \mathrm{~mm}$ & 15,89 & 1,08 & \\
$20 \mathrm{~mm}$ & 17,66 & 1,20 & $\mathrm{E}=0,35$ \\
$22 \mathrm{~mm}$ & 19,43 & 1,32 & \\
& & & $\mathrm{E}=0,50$ \\
$18 \mathrm{~mm}$ & 15,6 & 1,70 & \\
$20 \mathrm{~mm}$ & 17,34 & 1,89 & \\
$22 \mathrm{~mm}$ & 19,07 & 2,08 & $\mathrm{E}=0,65$ \\
& & 0,94 & \\
\hline
\end{tabular}

Deneme ağlarının en uygun modele göre çizdirilen seçicilik eğrileri, her ağın yakaladığı balıkların \% frekans dağılımları ile birlikte Şekil 3, 4 ve 5'te verilmiştir. Aynı göz genişliği için en uygun modellerden elde edilen karşılaştırmalı seçicilik eğrileri de Şekil 6, 7 ve 8' de verilmiştir. 


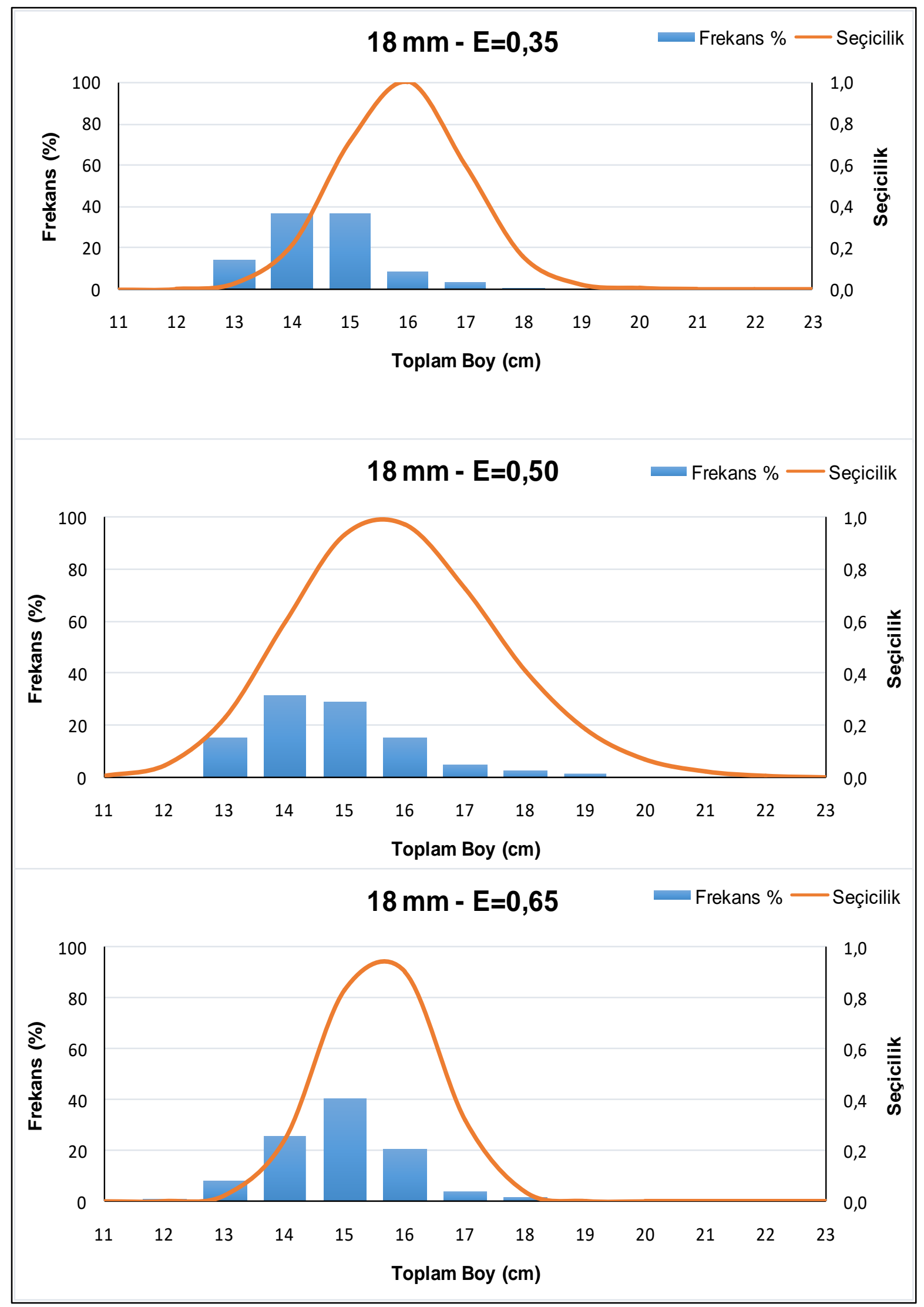

Şekil 3. Farklı donam faktörlerinde $18 \mathrm{~mm}$ göz genişliğindeki ağlara yakalanan izmarit balıklarının boy - \% frekans dağılımları ve seçicilik eğrileri 


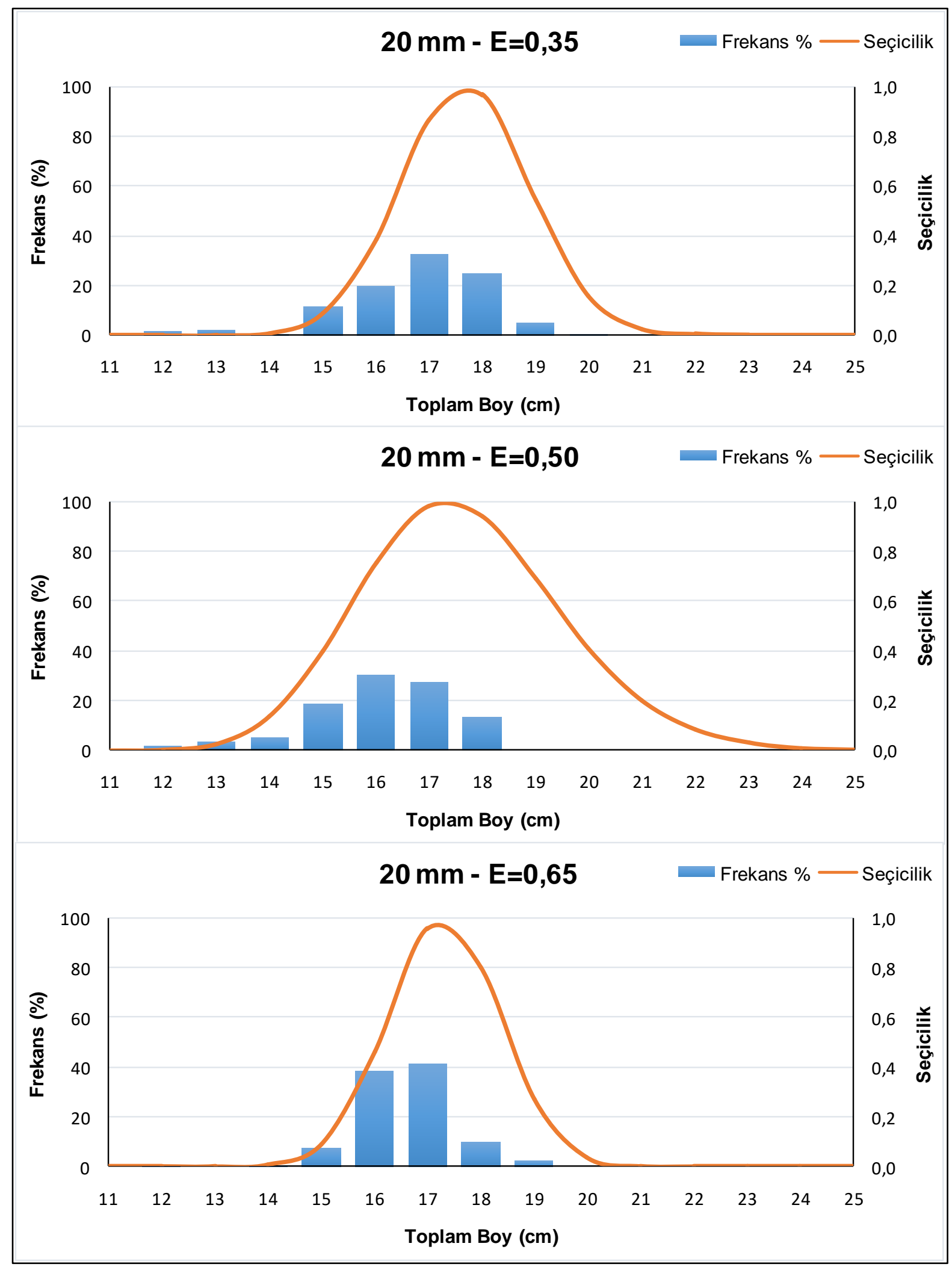

Şekil 4. Farklı donam faktörlerinde $20 \mathrm{~mm}$ göz genişliğindeki ağlara yakalanan izmarit balıklarının boy - \% frekans dağılımları ve seçicilik eğrileri 


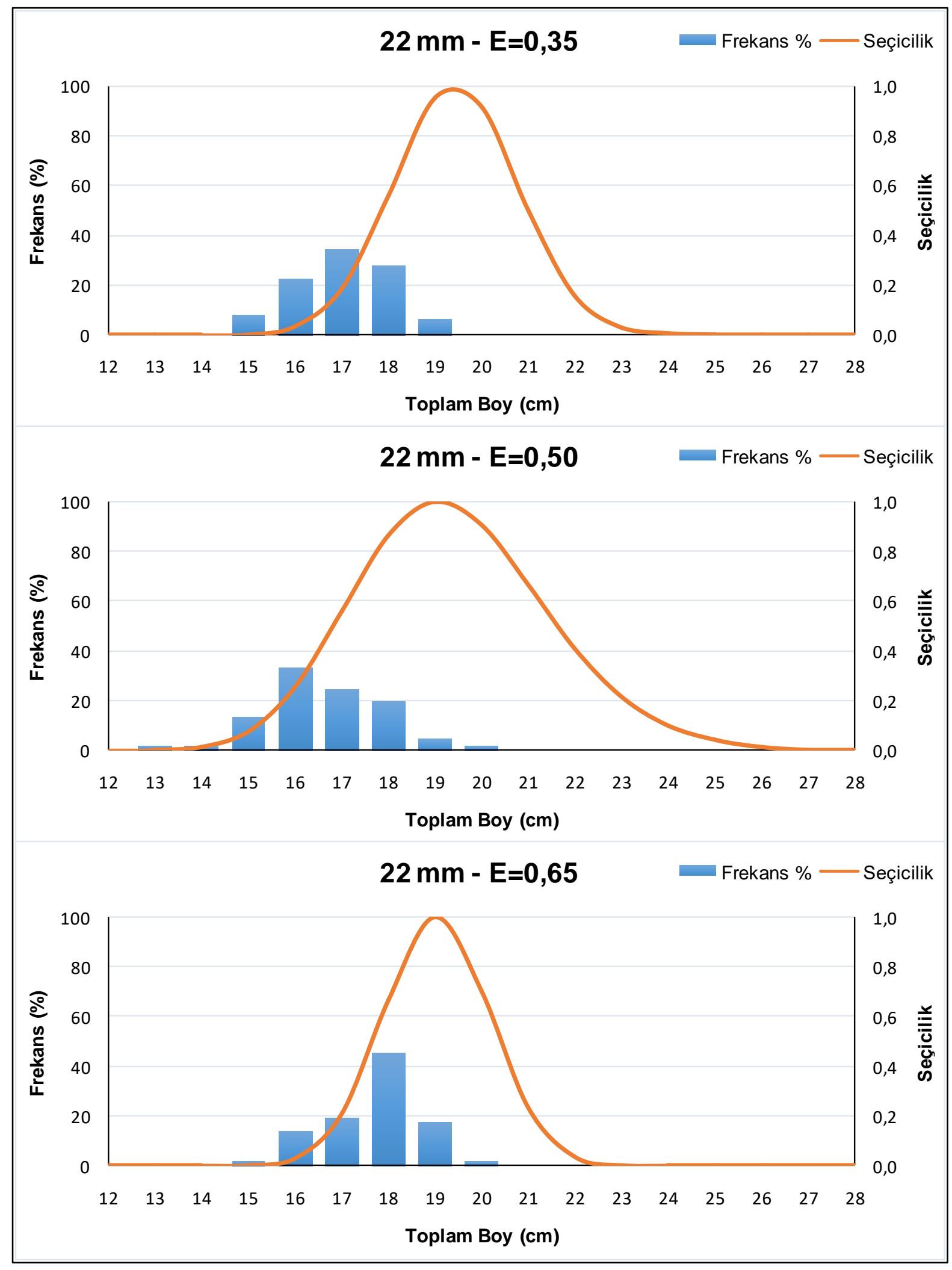

Şekil 5. Farklı donam faktörlerinde $22 \mathrm{~mm}$ göz genişliğindeki ağlara yakalanan izmarit balıklarının boy - \% frekans dağılımları ve seçicilik eğrileri 


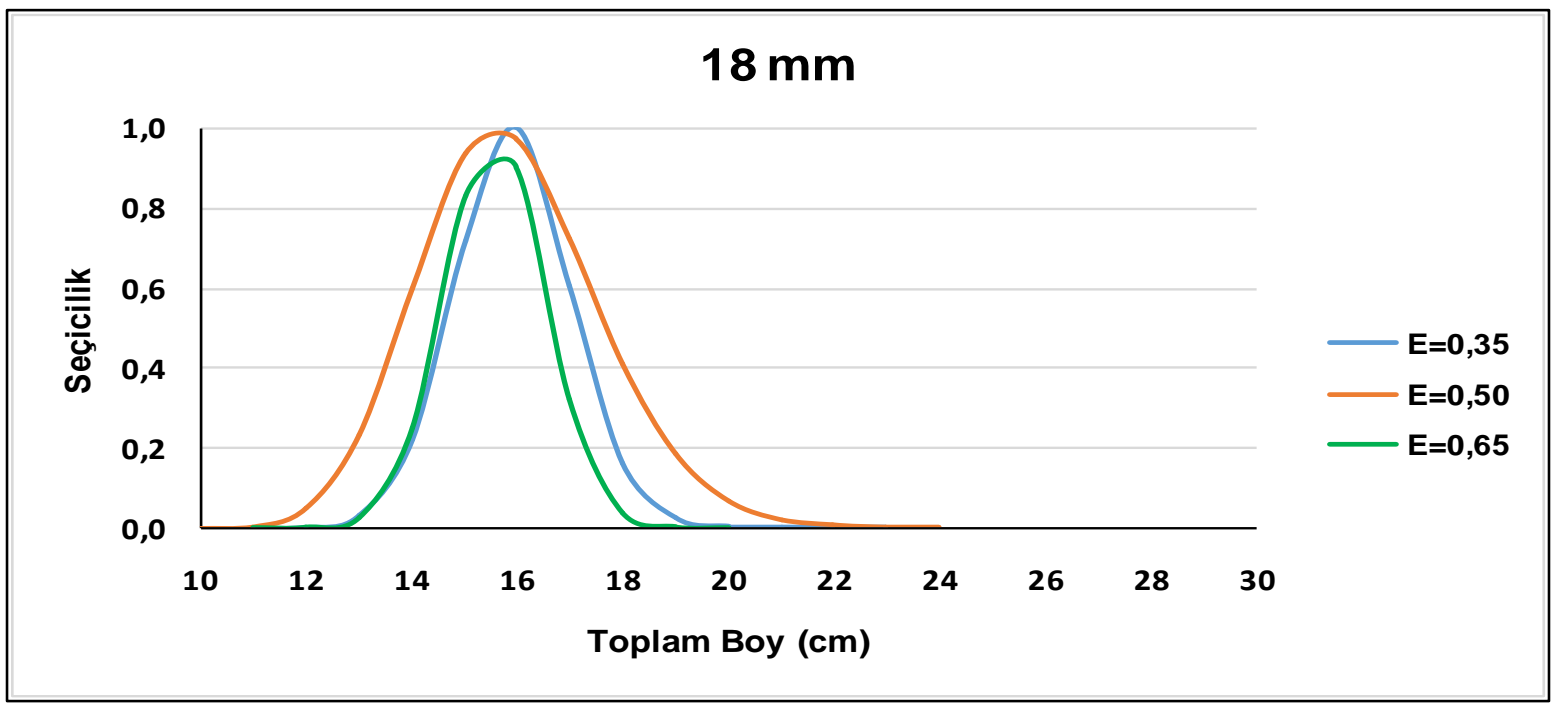

Şekil 6. Farklı donam faktörlerine sahip 18 mm göz genişliğindeki ağların izmarit balığı için seçicilik eğrilerinin karşılaştırması

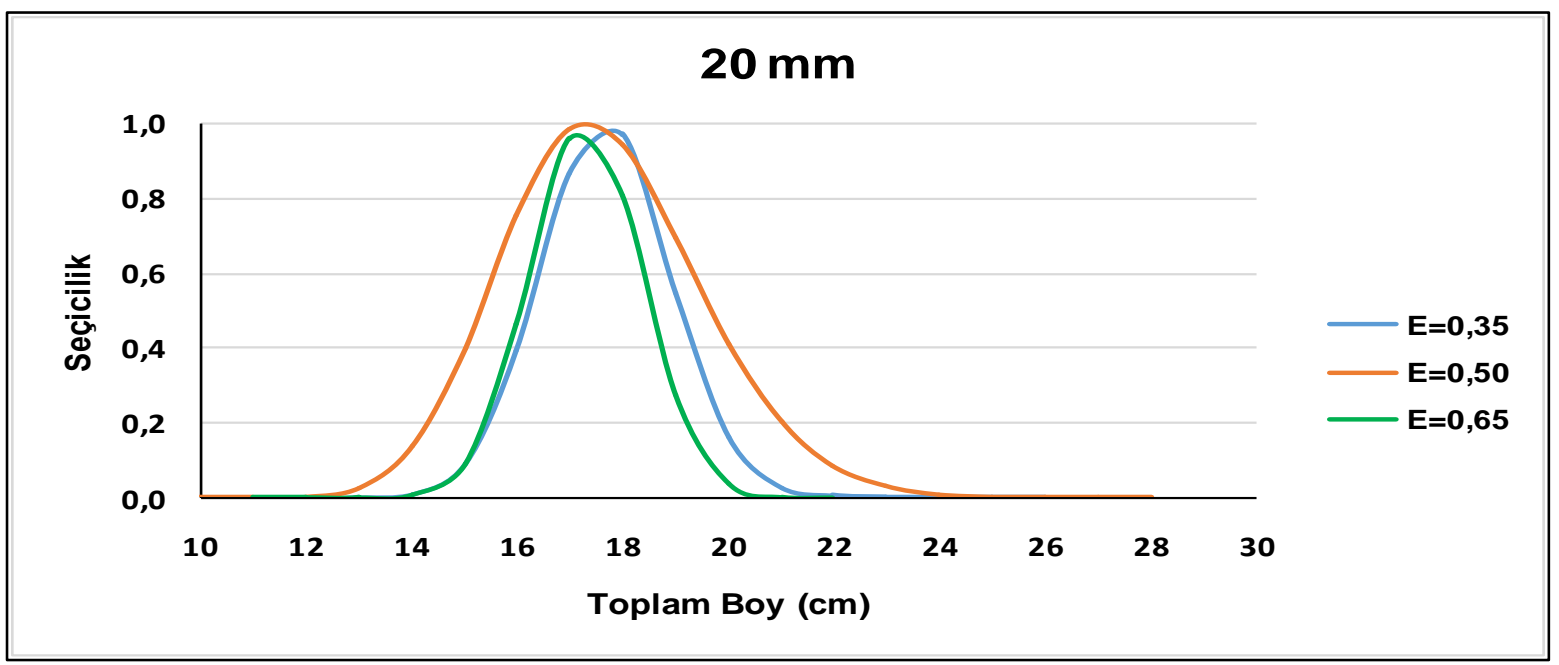

Şekil 7. Farklı donam faktörlerine sahip 20 mm göz genişliğindeki ağların izmarit balığı için seçicilik eğrilerinin karşılaştırması

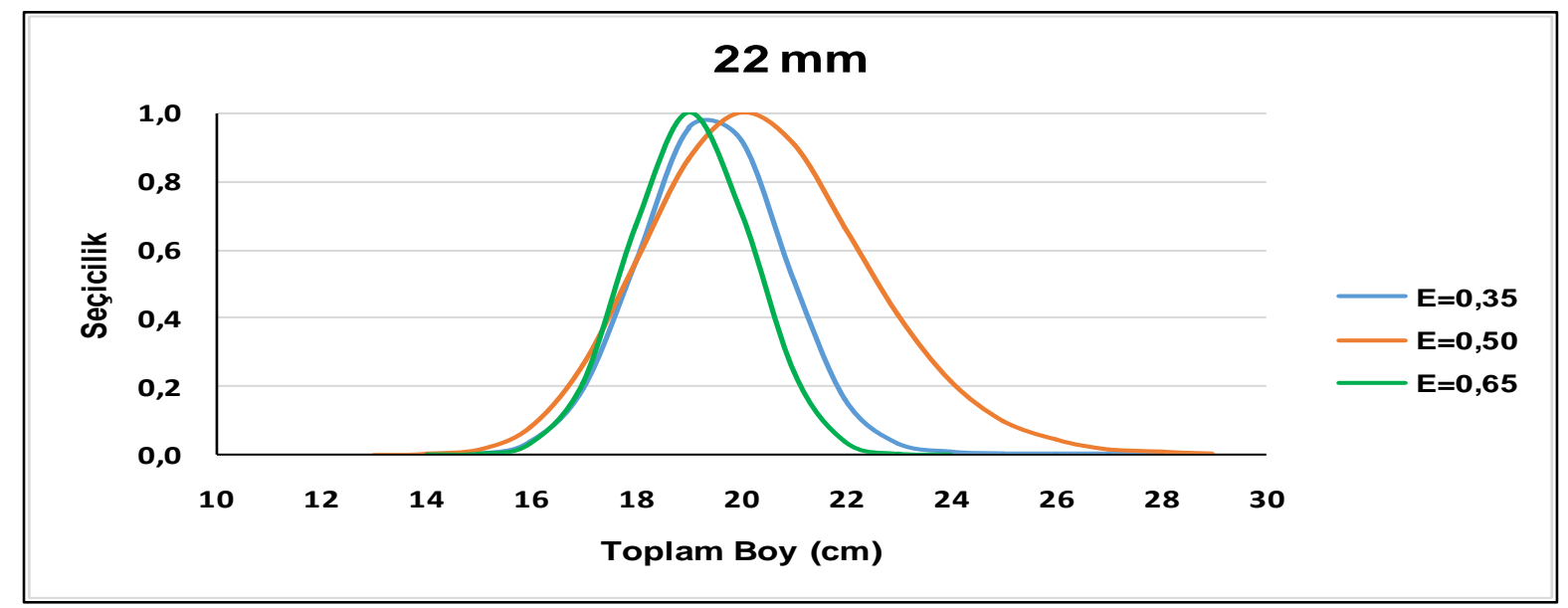

Şekil 8. Farklı donam faktörlerine sahip 22 mm göz genişliğindeki ağların izmarit balığı için seçicilik eğrilerinin karşılaştırması 


\section{Tartışma ve Sonuç}

Çalışmada adet olarak en fazla yakalan tür izmarit balığı olmuştur. Denemelerde 1226 adet ve $52,227 \mathrm{~kg}$ izmarit balığı yakalanmıştır. Bu balık için yapılan seçicilik hesaplamalarında, $\mathrm{E}=0,35$ donam faktöründeki ağlar için "bi-modal", $\mathrm{E}=0,50$ donam faktörü için "lognormal", $E=0,65$ donam faktörü için ise "normal scale" modeli en iyi sonucu vermiştir.

Tablo 1 incelendiğinde aynı göz genişliğinde farklı donam faktörlerindeki ağların yakaladıkları balıkların boy dağılımlarının birbirine çok yakın değerlerde olduğu görülmektedir. Aynı durum ağlar için elde edilen optimum yakalama boyları ve yayılım değerlerine de yansımıștır. Optimum yakalama boyu ve eğrilerin yayılım değerleri arasındaki küçük farklılıkların hesaplama modellerinden kaynaklandığı düşünülmektedir. Ağlarda kullanılan donam faktörü farkının izmarit balığı için seçiciliğe etkisinin olmadığ 1 görülmüştür.

Metin ve diğ. (1998), İzmir Körfezi'nde yaptıkları çalışmada $\mathrm{E}=0,50$ donam faktöründe $18 \mathrm{~mm}, 20 \mathrm{~mm}$, $22 \mathrm{~mm}$ göz genişliğindeki barbun ağlarının izmarit balığı için optimum yakalama boylarını sırası ile, 15 $\mathrm{cm}, 16,67 \mathrm{~cm}$ ve $18,33 \mathrm{~cm}$ olarak belirlemişlerdir. Gökçeada kıyılarında yapılan bir çalışmada da aynı göz genişlikleri için optimum boy değerlerini sirasiyla $15,1 \mathrm{~cm}, 16,78 \mathrm{~cm}$ ve $18,46 \mathrm{~cm}$ olarak hesaplamışlardır (Karakulak ve Erk, 2008). Çalışmamızda aynı ağlar için bu değerler sırası ile $15,6 \mathrm{~cm}, 17,34 \mathrm{~cm}$ ve 19,04 olarak belirlenmiştir (Tablo 3). Bu duruma neden olarak, çalışmaların yapıldığı bölgelerdeki balıkların boy dağılımı ve mevsimsel farklılıklar gösterilebilir.

Yunanistan kıyılarında yapılan bir araştırmada izmarit balığının ilk üreme boyu dişi bireyler için 9,1 $\mathrm{cm}$ bulunmuştur (Stergiou ve diğ., 1997). İzmir Körfezi'nde yapılan bir çalışmada ise ilk üreme boyu dişillerde 11,51 cm, erkeklerde 13,12 cm olarak belirlenmiştir (Soykan ve diğ., 2010). Proje çalışmasında izmarit balığı için hesaplanan optimum yakalama boyu ve seçicilik eğrilerinin yayılım değerleri dikkate alınarak yapılan değerlendirme sonucunda, deneme ağlarının yakaladığı balıkların boylarının ilk üreme boyundan büyük oldukları görülmüştür, ancak $18 \mathrm{~mm}$ göz genişliğindeki yakaladıkları balıkların boy gurubunun ilk üreme boyuna yakın değerlerde av yaptığı gözlenmiştir. Bundan dolayı bu balığın avcılığında $20 \mathrm{~mm}$ göz genişliğinden küçük ağların kullanımı çok doğru olmayacaktır. Nitekim önceki yapılan çalışmalarda (Metin ve diğ., 1998; Karakulak ve Erk, 2008) optimum yakalama boyları bizim çalışmamızdan daha küçük olduğu da görülmüştür. Gıda Tarım ve Hayvancılık Bakanlığı'nın yayınladığı 4/1 Numaralı Ticari amaçlı Su Ürünleri Avcılığının Düzenlenmesi Hakkında Tebliğ'de izmarit balığı için yasal yakalama boyu limiti bulunmamaktadır.
Deneme ağlarına en fazla yakalanan izmarit balığ için donam faktörü farkına dayalı bir seçicilik farkı belirlenememiştir. Ancak $18 \mathrm{~mm}$ göz genişliğindeki ağlar için hesaplanan optimum boy ve eğrilerin yayılım değerlerinin, izmarit balığı için hesaplanan ilk üreme boyuna yakın değerleri içerdiği belirlenmiştir.

Sonuç olarak, tekir ve barbun avcılığında kullanılacak galsama ağlarının hedef ve hedef dış1 türler göz önüne alındığında, $\mathrm{E}=0,50$ donam faktörüne sahip ağaların, en geniş seçicilik aralığını vermesi, $\mathrm{E}=0,35$ donam faktörüne sahip ağlar ile 18 mm göz genişliğine sahip ağların küçük balıkları yakalamaları nedeniyle Kuzey Ege Denizi'nde E= 0,50 donam faktöründen daha büyük donama ve 18 mm'den daha büyük göz genişliğine sahip ağların kullanılması gerektiği belirlenmiştir.

\section{Teşekkür}

$\mathrm{Bu}$ çalışma TÜBİTAK 1150897 no'lu proje tarafından desteklenmiştir. $\mathrm{Bu}$ çalışmada yardımlarını esirgemeyen Osman Odabaşı, Erman Uğur, Ogün Şirin, Ergün Tanay ve Hayati Yağlı 'ya teşekkürlerimizi bir borç biliriz.

\section{Kaynaklar}

Ayaz A., İşmen İ., Özekinci U., Altınağaç U., Özen Ö., Yığıı C.Ç., Cengiz Ö., Ayyıldız H., \& Öztekin, A. 2010. Kuzey Ege'de Dip Uzatma Ağlarının Seçiciliği ve Hedef Dışı av Oranlarının Belirlenmesi Üzerine Araştırmalar Tübitak Proje No: 106Y021 p:177

Brandt, A.V. 1984. Fish catching methods of the world, Fishing News Books Ltd., Farnham, Surrey, England, Pp: 418.

Bolat, Y., \& Tan, D., 2017. Selectivity of multifilament trammel nets of different mesh sizes on the red mullet (Mullus barbatus L., 1758) in Western Mediterranean, Turkey. Iranian Journal of Fisheries Sciences 16 (1); 127-137

Clark, J.R. 1960. Report on Selectivity of Fishing Gear., In Fishing effort, and effect of fishing on resources and the selectivity of fishing gear. ICNAF Spec. Publ. 2: 27-56.

Dinçer, A.C., \& Bahar, M. 2008. Multifilament Gillnet Selectivity for the Red Mullet (Mullus barbatus) in the Eastern Black Sea Coast of Turkey, Trabzon. Turkish Journal of Fisheries and Aquatic Sciences 8: 355-359.

Hamley, J.M. 1975. Review of Gillnet Selectivity, Journal of the Fisheries Research Board of Canada, 32, 1943-1969.

Holst, R., Madsen, N., Moth-Poulsen, T., Fonseca, P., Campos, A. 1998. Manual for Gillnet Selectivity. European Commission. 
Hoşsucu, H. 2002. Balıkçılık I, Avlanma Araçları ve Teknolojisi, Ege Üniversitesi Su Ürünleri Fakültesi Yayınları No:55, Ders Kitabı Dizini No:24 Ege Üniversitesi Ege Meslek Yüksekokulu Basımevi Bornova-İzmir.

Hovgard, H., \& Lassen, H. 2000. Manual on estimation of selectivityfor gillnet and longline gears in abundance surveys, FAO Fisheries Technical Paper No:397, Rome p: 84

Hubert, W. A., Pope, K. L., \& Dettmers, J. M. 2012. Passive capture techniques. Pages 223-265 in A. V. Zale, D. L. Parrish, and T. M. Sutton, editors. Fisheries techniques, 3rd edition. American Fisheries Society, Bethesda, Maryland.

Kalaycı, F., \& Yeşilçiçek, T. 2012. Investigation of the Selectivity of Trammel Nets Used in Red Mullet (Mullus barbatus) Fishery in the Eastern Black Sea, Turkey. Turkish Journal of Fisheries and Aquatic Sciences 12: 937-945 Doi:10.4194/1303-2712-v12_4_21

Kara, A. 1992. Ege Bölgesi Uzatma Ağları Balıkçılığı ve Geliştirilmesi Üzerine Araştırmalar, (Dokta Tezi.), Ege Üniversitesi Fen Bilimleri Enstitüsü.

Karakulak, F.S., Erk, H. 2008. Gill net and trammel net selectivity in the northern Aegean Sea, Turkey, Scientia Marina, 72, 527-540.

Karlsen, L., Bjarnason, B.A. 1987. Small-scale fishing with driftnets. FAO Fish. Tech. Pap., 284.

Kolding, J., Skålevik, Å. 2017. Pasgear 2. A data base package for experimental or artisanal fishery data from passive gears. Version 2.10. available at: http://www.imr.no/forskning/utviklingssamarbei d/eaf_nansen_programmet/pasgear_2/en

Kumova, C. A. 2013. Galsama Ağlarında Donam Faktörünün, Av Verimi Ve Seçiciliğe Etkisi. Çanakkale Onsekiz Mart Üniversitesi Fen Bilimleri Enstitüsü Su Ürünleri Anabilim Dalı Yüksek Lisans Tezi s:63.

Kumova, C. A., Altınağaç, U., Öztekin, A., Ayaz, A., \& Aslan, A. 2015. Effect of Hanging Ratio on Selectivity of Gillnets for Bogue (Boops boops, L. 1758). Turkish Journal of Fisheries and Aquatic Sciences 15: 561-567 Doi: 10.4194/1303-2712v15_2_44

Metin, C., Lök, A., İlkyaz, T.A. 1998. Faklı Göz Genişliğine Sahip Dip Uzatma Ağlarında Isparoz (Diplodus annularis Lin.,1758) ve İzmarit (Spicara flexuosa Rafinesque, 1810) Balıklarının Seçiciliği, E. Ü. Su Ürünleri Derg., 15, 293-303.

Millar, R.B. 1992. Estimating the Size-Selectivity of Fishing Gear by Conditioning on the Total Catch, Journal of the American Statistical Association, 87, 962-968.
Millar, R.B., Holst, R. 1997.Estimation of gillnet and hook selectivity using log-linear models, Ices Journal of Marine Science, 54, 471-477.

Millar, R.B., Fryer, R.J. 1999. Estimating the sizeselection curves of towed gears, traps, nets and hooks, Reviews in Fish Biology and Fisheries, 9, 89-116

Özdemir S., Erdem, Y., \& Sümer, Ç. 2005. Farklı Yap1 ve Materyale Sahip Uzatma Ağlarının Av Verimi ve Av Kompozisyonu Frrat Üniversitesi, Fen ve Mühendislik Bilimleri Dergisi.17 (4), s: 621-627.

Soykan, O., İlkyaz, A.T. Metin G., Kınacigil, H.T. 2010. Growth and reproduction of blotched picarel (Spicara maena Linnaeus, 1758) in the central Aegean Sea, Turkey. Turk. J. Zool. 34:453-459.

Stergiou, K.I., Christou, E.D., Georgopoulous, D., Zenetos A., Souvermezoglou, C. 1997. The Hellenic seas: physics, chemistry, biology and fisheries. p. 415-538. In A.D. Ansell, R.N. Gibson and M. Barnes (eds.). Oceanography and marine biology: an annual review. UCL Press

Ünsal, S., \& Kara, A. 1996. Avcılık yöntemlerinin sınıflandırılması, E.Ü. Su Ürünleri Dergisi, İzmir, v.13, p: 461-469.

Yüksel, F., Aydın, F. 2012. Galsama Ağlarının Seçiciliği ve Seçiciliği Etkileyen Faktörler.eJournal of New World Sciences Academy 2012, Volume: 7, Number: 2, ArticleNumber: 5A0070 